\title{
Differential transcription of ribosomal cistrons denoting nucleolar dominance in hybrids of Drosophila mulleri and Drosophila navojoa (mulleri complex, Repleta group)
}

\author{
Leliane Silva Commar ${ }^{1}$, Hermione E.M.C. Bicudo ${ }^{2}$, Paula Rahal ${ }^{2}$ and Carlos Roberto Ceron ${ }^{1}$ \\ ${ }^{1}$ Departamento de Química e Ciências Ambientais, Universidade Estadual Paulista, São José do Rio Preto, \\ SP, Brazil. \\ ${ }_{2}^{2}$ Departamento de Biologia, Universidade Estadual Paulista, São José do Rio Preto, SP, Brazil.
}

\begin{abstract}
The fruit flies Drosophila mulleri and Drosophila navojoa are included in the mulleri complex of the mulleri subgroup and Repleta group. Although there is no demonstration that interspecific crosses between them occur in nature, they intercross in the laboratory in both cross directions. Previous data have shown the occurrence of nucleolar dominance in interspecific hybrids of some species in the mulleri complex. We investigated nucleolar dominance in $D$. mulleri/D. navojoa hybrids using the transcription profiles of the rDNA internal transcribed spacer (ITS-1) region. The results showed that the ribosomal cistrons present in the $\mathrm{X}$ chromosome and in the microchromosome of $D$. navojoa are exclusively or preferentially transcribed in these hybrids depending on the cross direction, denoting the complete or partial nucleolar dominance of this species over D. mulleri.
\end{abstract}

Key words: Drosophila mulleri, D. navojoa, interspecific hybrids, nucleolar dominance, rDNA.

Received: December 15, 2006; Accepted: May 17, 2007.

In animals and plants the rRNA gene family consists of tandemly arrayed repeats of the $18 \mathrm{~S}, 5.8 \mathrm{~S}$, and $28 \mathrm{~S}$ structural genes (Long and Dawid 1980). Each transcription unit is composed of an external transcribed spacer (ETS) leader promoter region, an $18 \mathrm{~S}$ rRNA coding region, a noncoding internal transcribed spacer (ITS-1), a 5.8S rRNA coding region, a second noncoding ITS region (ITS-2), a 28S rRNA coding region, and, finally, a nontranscribed intergenic spacer segment (IGS) (Hillis and Dixon, 1991, Polanco et al., 1998). Regulatory regions are located in the intergenic spacer (IGS) region and typically include a promoter and arrays of internal sub-repeats thought to act as transcription enhancers (Busby and Reeder, 1983,Pikaard, 2000a). In addition to regulatory studies, the IGS, ITS1 and ITS2 regions have been used for species characterization in taxonomy studies (Mateos and Markow, 2005, Djadid et al., 2006, Mateus et al., 2006).

Studies on interspecific hybrids have shown dominance of the nucleolar organizing activity of one parental species over another, this process having been documented in both animals (Honjo and Reeder, 1973, Bicudo and

Send correspondence to Carlos Roberto Ceron. Departamento de Química e Ciências Ambientais, Universidade Estadual Paulista "Júlio de Mesquita Filho", Rua Cristóvão Colombo 2265, 15055-000 São José do Rio Preto, SP, Brazil. E-mail: ceron@ ibilce.unesp.br.
Richardson, 1977) and plants (Wallace and Landridge, 1971, Pikaard, 2000b). Nucleolar dominance occurs when one parental set of ribosomal RNA (rRNA) genes is transcribed but the rRNA genes inherited from the other parent are silent (Grummt and Pikaard, 2003). In Drosophila, nucleolar dominance has been observed in interspecific hybrids from crosses between Drosophila melanogaster and Drosophila simulans (Durica and Krider, 1978) and in hybrids of species from the Repleta group mulleri complex (Bicudo and Richardson, 1977, Bicudo, 1981, Leoncini et al., 1996).

In species from the Repleta group mulleri complex, the nucleolus organizer region (NOR) is present in the $\mathrm{X}$ chromosome and in the microchromosome (Bicudo and Richardson, 1977; 1981). The microchromosome is pair 6 in the metaphase plate of repleta group species, corresponding to Muller's element F (González et al., 2002). Bicudo and Richardson (1981) considered the occurrence of rDNA cistrons in the microchromosome of mulleri complex species an example of genetic homology, supporting the view of a common phylogenetic origin for the $\mathrm{X}$ chromosome and the microchromosome in Drosophila. In hybrids involving Drosophila mulleri and Drosophila arizonae (also a mulleri complex species), cytogenetic data have suggested that the ribosomal cistrons present in the $\mathrm{X}$ chromosome and microchromosomes of D. arizonae are dominant 
over those from D. mulleri (Bicudo and Richardson, 1977; Bicudo, 1981; Oliveira et al., 2006). The confirmation of this fact came from molecular studies (Leoncini et al., 1996; Baffi and Ceron, 2002). In addition, cytogenetic studies involving hybrids of D. mulleri and other species in the mulleri complex have indicated different classes of nucleolar dominance, with $D$. mulleri NORs being dominant over those of Drosophila wheeleri and Drosophila aldrichi but recessive when associated with NORs from Drosophila navojoa or Drosophila mojavensis in hybrids (Bicudo, 1981).

We used differential transcription of ITS-1 rRNA genes to investigate nucleolar dominance in hybrids between D. mulleri (from Guayalejo Tamazunchale, México) and D. navojoa (from Tehuantepec, México), D. mulleri belonging to the mulleri cluster of the mulleri complex whereas D. navojoa is included in the mojavensis cluster of the same complex (Vilela, 1983, Wasserman, 1992). Bicudo (1981) obtained laboratory hybrid males and females of these species only in the direction $D$. mulleri females and D. navojoa males, although in our study reciprocal crosses also yielded males and females. The flies used were verified as hybrids by analysis of the EST- 5 esterase band before RNA extraction, this being possible because the $D$. mulleri we used was homologous for the slow form of this esterase while the $D$. navojoa was homologous for the fast form of the enzyme so that hybrid flies showed the two bands simultaneously in polyacrylamide gels.

The Trizol method (GIBCO BRL Technologies, U.S.A.) was used to extract total RNA from single parental and hybrid male and female flies frozen at $-70{ }^{\circ} \mathrm{C}$. After treatment with RQ 1 RNase-Free DNase (Promega, U.S.A.) the RNA was submitted to reverse transcription polymerase chain reaction (RT-PCR) amplification to obtain the cDNA single stranded fragment corresponding to rRNA ITS-1 utilizing the 5'GCTGCGTTCTTCATCGA C3' oligonucleotide as a reverse primer. The thermocycling profile consisted of $5 \mathrm{~min}$ at $25^{\circ} \mathrm{C}$ for annealing the reverse primer, plus $60 \mathrm{~min}$ at $42^{\circ} \mathrm{C}$ for extension of the chain, followed by incubation at $70^{\circ} \mathrm{C}$ for $15 \mathrm{~min}$ for enzyme inactivation. A second PCR amplification reaction utilizing the 5' CCTAACAAGGTTTCCGTACC3' oligonucleotide allowed us to obtain a double-stranded amplified cDNA fragment corresponding to the entire ITS- 1 sequence of the parental species and hybrids. In this step the thermocycling profile consisted of incubation at $95^{\circ} \mathrm{C}$ for $2 \mathrm{~min}$, followed by 35 cycles of $1 \mathrm{~min}$ at $95^{\circ} \mathrm{C}, 1 \mathrm{~min}$ at $50^{\circ} \mathrm{C}$ and $1 \mathrm{~min}$ at $72{ }^{\circ} \mathrm{C}$ plus a final extension for $2 \mathrm{~min}$ at $72{ }^{\circ} \mathrm{C}$.

A small number of hybrids was produced in the two directions of crosses involving D. mulleri and D. navojoa. We tried to analyze all of them, but the RNA extracted from hybrids was not good enough to detect the transcription pattern in every fly. Thus, in the $D$. mulleri female $\mathrm{X} D$. navojoa male crosses 10 hybrid males obtained but only four could be analyzed, while none of the three hybrid fe- males showed good results. In the reciprocal crosses ( $D$. navojoa females X D. mulleri males) only two of eight hybrid males and four of 9 hybrid females showed transcription patterns that could be analyzed.

The ITS-1 cDNA amplified fragment from $D$. mulleri was about $620 \mathrm{bp}$ long while in $D$. navojoa this fragment was about 500 bp long (Figure 1). In hybrid males from crosses involving $D$. mulleri females and $D$. navojoa males (hybrids bearing an $\mathrm{X}$ chromosome from D. mulleri and microchromosomes from both species), the cDNA amplified fragment corresponding to the ITS-1 region displayed a length of $500 \mathrm{bp}$, indicating that, in this case, transcribed RNA comes from the D. navojoa genome. As mentioned, females were not analyzed because none of them showed good results in this cross direction.

In the reciprocal crosses involving $D$. mulleri males and D. navojoa females (Figure 2), hybrid males (bearing an X chromosome from $D$. navojoa and microchromosomes from both species) and females (bearing X chromosome and microchromosomes from both species) presented two fragments of 500 and $620 \mathrm{bp}$, showing that in this direction of crosses rRNA genes of both species are transcribed. However, rRNA genes from D. navojoa seem to have been transcribed at a higher level, as indicated by the degree of fluorescence of the gel bands.

The results obtained in this study indicate that there is complete nucleolar dominance of $D$. navojoa in $D$. mulleri female/ $D$. navojoa male hybrids. In this case, the $500 \mathrm{bp}$ fragment corresponds to the amplification of the rRNA ITS-1 region located in the microchromosome from the parental $D$. navojoa male which is then activated in the hybrid males while the NOR in the $D$. mulleri $\mathrm{X}$ chromosome remains suppressed. Cytogenetical studies by Bicudo (1981) in this cross direction had already suggested dominance of D. navojoa NOR over D. mulleri NOR.

As mentioned above, in females obtained in reciprocal crosses (D. mulleri males and D. navojoa females), tran-

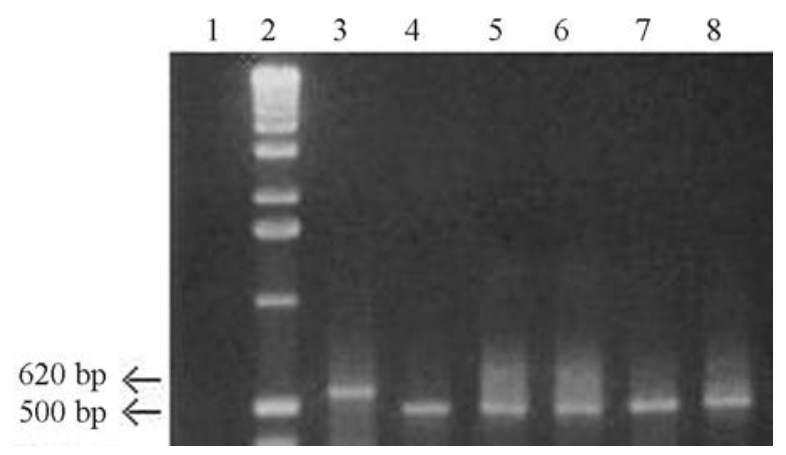

Figure 1 - Amplified cDNA internal transcribed spacer (ITS-1) intergenic spacer (IGS) fragments obtained from hybrids of crosses between Drosophila mulleri females and Drosophila navojoa males using the reverse transcriptase polymerase chain reaction (RT-PCR) and visualized in $2.5 \%(\mathrm{w} / \mathrm{v})$ agarose gel. Lanes are as follows: (1) water; (2) $1 \mathrm{~kb}$ DNA ladder marker; (3) D. mulleri parental female; (4) D. navojoa parental male; (5), (6), (7) and (8) hybrid males. 


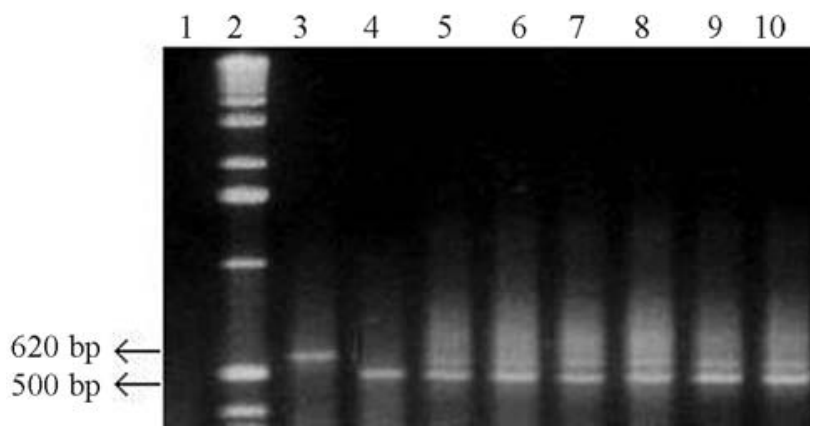

Figure 2 - Amplified cDNA internal transcribed spacer (ITS-1) intergenic spacer (IGS) fragments obtained from hybrids of crosses between Drosophila mulleri males and Drosophila navojoa females using the reverse transcriptase polymerase chain reaction (RT-PCR) and visualized in $2.5 \%(\mathrm{w} / \mathrm{v})$ agarose gel. Lanes are as follows: (1) water; (2) $1 \mathrm{~kb}$ DNA ladder marker; (3) D. mulleri parental male; (4) D. navojoa parental female; (5) and (6) hybrid males; (7) (8), (9) and (10) = hybrid females.

scription of the ribosome cistrons from both species was observed but at apparently different levels, suggesting that in these hybrid females the transcription of the ribosome cistrons from $D$. navojoa $\mathrm{X}$ chromosome partially suppressed the transcription of the NOR from the D. mulleri X chromosome. In the hybrid males obtained in the same cross direction both the NOR from the X chromosome of $D$. navojoa (the only X present) and the NOR of D. mulleri microchromosome are operating. In the next step of this research we plan to use quantitative PCR to produce more accurate information regarding the degree nucleolar dominance.

On the basis of these data we cannot say if the NORs of both microchromosomes are also active in females or if, in males, the $D$. navojoa microchromosome NOR is also being transcribed. However, data from D. mulleri/D. arizonae hybrids indicated that the dominant microchromosome NOR is activated only when the $\mathrm{X}$ chromosome NOR from the same species is absent, thus acting as a secondary NOR (Bicudo and Richardson, 1977). If the situation is the same for mulleri/navojoa hybrids, the microchromosome NORs from both parents should not operate in females (where both X-NORs are present) and the $D$. navojoa microchromosome NOR is also not expected to operate in males because the $D$. navojoa $\mathrm{X}-\mathrm{NOR}$ is present.

The complete dominance observed in males from the cross direction involving $D$. mulleri females and $D$. navojoa males and the partial dominance operating in the cross direction involving $D$. navojoa females and $D$. mulleri males differs from the apparently complete dominance observed in hybrids from both cross directions involving D. mulleri and D. arizonae (Bicudo and Richardson, 1977). Such findings suggest regulatory differentiation between $D$. arizonae and $D$. navojoa in the evolutionary process which produced these species, reinforcing once more the concept that modifications in the regulatory mechanisms have had a very important role in speciation (Ohno, 1969, Carson, 1976).

A mechanism frequently considered to work in NORs dominance in hybrids is the "enhancer imbalance" model in which differences in the sequence or number of regulatory elements in the ITS regions results in a greater binding affinity for transcription factors to the dominant genes (Honjo and Reeder, 1973, Flavell, 1986). However in the marine copepod Tigriopus californicus, data obtained by Flowers and Burton (2006) showed that repetitive elements in the IGS are not required for the uniparental gene silencing of rRNA transcription. The continuation of studies on $D$. mulleri/D. navojoa hybrids seems to be a promising way to focus on resolving this ambiguity.

\section{Acknowledgments}

We thank the Brazilian agency CAPES for providing a Master's degree fellowship for Leliane Silva Commar and we are grateful to Eliani Nobuco Ikeguchi Ohira for technical support.

\section{References}

Baffi M and Ceron CR (2002) Molecular analysis of the rDNA ITS-1 Intergenic spacer in Drosophila mulleri, D. arizonae, and their hybrids. Biochem Genet 40:411-421.

Bicudo HEMC (1981) Further observations on the nucleolar organizing activity in salivary gland cells of Drosophila mulleri, D. arizonensis and their hybrids. Biol Zbl 100:597-612.

Bicudo HEMC and Richardson RH (1977) Gene regulation in Drosophila mulleri, D. arizonensis, and their hybrids: The nucleolar organizer. Proc Natl Acad Sci 74:3498-3502.

Bicudo HEMC and Richardson RH (1981) Location of ribosomic cistrons in the salivary gland cells of D.mulleri, D. arizonensis and their hybrids. Braz J Genet 4:477-481.

Busby SJ and Reeder RH (1983) Spacer sequences regulate transcription of ribosomal gene plasmids injected into Xenopus embryos. Cell 34:989-996.

Carson HL (1976) The unit of genetic change in adaptation and speciation. Ann Missouri Bot Gard 63:210-223.

Djadid ND, Gholizadeh S, Aghajari M, Hassan Zehi AG, Raeisi A and Zakeri S (2006) Genetic analysis of rDNA-ITS2 and RAPD loci in field populations of the malaria vector, Anopheles stephensi (Diptera, Culicidae): Implications for the control program in Iran. Acta Trop 97:65-74.

Durica DS and Krider HM (1978) Studies on ribosomal RNA cistrons in interspecific Drosophila hybrids. 2. Heterochromatic regions mediating nucleolar dominance. Genetics 89:37-64.

Flavell RB (1986). The structure and control of expression of ribosomal RNA genes. Ox Surv Plant Mol Cell Biol 3:252274.

Flowers JM and Burton RS (2006) Ribosomal RNA gene silencing in inter-population hybrids of Tigriopus californicus: Nucleolar dominance in the absence of inter-genic spacer subrepeats. Genetics 173:1479-1486.

Grummt I and Pikaard CS (2003) Epigenetic silencing of RNA polymerase I transcription. Nat Rev Mol Cell Biol 4:641649. 
González J, Ranz JM and Ruiz A (2002) Chromosomal elements evolve at different rates in the Drosophila genome. Genetics 161:1137-1154.

Hillis DM and Dixon MT (1991) Ribosomal DNA: Molecular evolution and phylogenetic inference. Q Rev Biol 66:411453.

Honjo T and Reeder RH (1973) Preferential transcription of Xenopus laevis ribosomal RNA in interspecies hybrids between Xenopus laevis and Xenopus mulleri. J Mol Biol 80:217-228.

Leoncini O, Tovar FJ and Bicudo HEMC (1996) Molecular evidence of ribosomal DNA (rDNA) Amplification of a minichromosome derived from Drosophila arizonae in $D$. mulleri-D. arizonae hybrid males. Braz J Genet 19:43-45.

Long EO and Dawid IB (1980) Repeated genes in eukaryotes. Annu Rev Biochem 49:727-764.

Mateos M and Markov TAM (2005) Ribosomal intergenic spacer (IGS) length variation across the Drosophilinae (Diptera, Drosophilidae). BMC Evol Biol 5:46-59.

Mateus RP, Ceron CR, Machado LPB and Sene FM (2006) Caracterização Preliminar do espaçador Interno Transcrito ITS-1 do DNA Ribossômico nas espécies do cluster buzzatii de Drosophila (Diptera, Drosophilidae). Ambiência 2:9096. (Abstract in English).

Ohno S (1969) The preferencial activation of maternally derived alleles in development of interspecific hybrids. In: Defendi
U (ed) Heterospecific Genome Interaction. Wistar Institute Press, Philadelphia, pp 137-150.

Oliveira CI, Bicudo HEMC and Itoyama MM (2006) New evidence for nucleolar dominance in hybrids of Drosophila arizonae and D. mulleri. Genet Mol Res 4:632-637.

Pikaard CS (2000a) The epigenetics of nucleolar dominance. Trends Genet 16:495-500.

Pikaard CS (2000b) Nucleolar dominance: Uniparental gene silencing on a multimegabase scale in genetic hybrids. Plant Mol Biol 43:163-177.

Polanco C, González AI, la Fuente A and Dover GA (1998) Multigene family of ribosomal DNA in Drosophila melanogaster reveals contrasting patterns of homogenization for iGS and ITS spacer regions: A posible mechanism to resolve this paradox. Genetics 149:243-256.

Vilela CR (1983). A revision of the Drosophila repleta species group (Diptera, Drosophilidae). Rev Bras Entomol 27:1114.

Wallace H and Landridge WHR (1971) Differential amphiplasty and the control of ribosomal RNA synthesis. Heredity 27:113 .

Wasserman M (1992) Cytological evolution of the Drosophila repleta species group. In: Krimbas CB and Powel JR (eds) Drosophila Inversion Polymorphism. CRC Press, Boca Raton, pp 455-552.

Associate Editor: Fabio de Melo Sene 